\title{
Effects of Intubation on heart rate: Xylocard and Esmolol
}

\author{
Mirza Afzal Baig ${ }^{1}$ \\ ${ }^{1}$ Department of Anaesthesiology, KBNIMS, Kalaburagi, Karnataka.
}

\section{Abstract}

Background: Lignocaine is a local anaesthetic of moderate potency and duration with good penetrative power and rapid onset of action carbonated lignocaine has remarkable penetrative power, rapid onset of action a high incidence of motor block and a reduced incidence of missed segments (When used for epidural anaesthesia) when compared to hydrochloride of lignocaine. Subjects and Methods: Seventy five (75) patients belonging to ASA grade $1 \& 2$ scheduled for general surgical, orthopaedic surgical, ENT, gynaecological surgical producers were studied. Results: The age of the patients varied from 10 to 60 years. In our study, the heart rate in controls (Group A) before induction was $86+/-10$ rose to $93+/-12$ and $107+/-13$ after induction and after laryngoscopy + ETI respectively. The changes seen after endotracheal intubation alone was statistically very highly significant $(<0.001)$. In Group B, the pre induction heart rate was $94+/-17$, which increased to $99+/-13$, after induction. This increase not significant $(\mathrm{P}>0.05)$. There was an increases of 15 at laryngoscopy + ETI which was very highly significant $(\mathrm{P}<0.001)$. Conclusion: In Group $\mathrm{C}$, the pre induction heart rate of $96+/-15$ increased to $97+/-11$ at induction and to $108+/-15$ following endotracheal intubation.

Keywords: Effects of Intubation, heart rate, Xylocard and Esmolol.

Corresponding Author: Dr. Mirza Afzal Baig, Department of Anaesthesiology, KBNIMS, Kalaburagi, Karnataka.

Received: May 2019

Accepted: June 2019

\section{Introduction}

Lignocaine was synthesized in 1943 by Lofgren and lundqvist in 1943 at A. B. Astra, Sweden. It was introduces into clinical practice by Gordh in 1948. Introduced as an antiarrhythmic agent in 1962 . Chemically it is an amide of xylidinedietyl amino 2:6 dimethy 1 acetanilide. It is very stable, not decomposed by boiling, acids or alkalies and withstands repeated autoclaving. The $\mathrm{pKa}$ of lignocaine is 7.90. At the normal tissue $\mathrm{pH}$ of 7.4 approximately $75 \%$ of lignocaine exists in the charged cationic form, while $25 \%$ exists in the nonionized form. At concentration of 2 microgram per milli litre, approximately $70 \%$ of the drug is bound to the plasma proteins. Lipid solubility is 2.9 .

Lignocaine is a local anaesthetic of moderate potency and duration with good penetrative power and rapid onset of action carbonated lignocaine has remarkable penetrative power, rapid onset of action a high incidence of motor block and a reduced incidence of missed segments (When used for epidural anaesthesia) when compared to hydrochloride of lignocaine. Tachyphylaxisoccus with repeated injections. Lignocaine causes vasodilation. Epinephrine prolongs the action of lignocaine and reduces its rate of systemic absorption. $^{[1]}$

Lignocaine is used in the treatment of ventricular dysrhythmias after myocardial infarction or cardic surgery. It depresses the rate of rapid depolarization without any effect on slow depolarization. This shortens the duration of action potential and effective refractory period in purkinje fibres and ventricular muscle, shortening of ERP in an area of tissue damage will result in impdulse being conducted in antegrade fashion, in case of unidirectional block. Hence retrograde conduction and re-entry fails to occur and therefore dysrhythmias ceases. ${ }^{[2,3]}$

Though true hypersensitivity to lignocaine has been reported, methylparaben a derivative of benzoic acid, which is used as a preservative, being highly antigenic, is the usual cause for hypersensitivity. Other side effects like nausea, drowsiness or dizziness can occur. At higher plasma levels, tremors, convulsions, bradycardia, decreased respiration with hypoxia, and cardiovascular collapse can ensue. ${ }^{[4]}$

Esmolol hydrochloride is chemically methyl $3-\{4-\{2-$ hydroxy-2-(isopophylamino) propoxy) phyenyl $\}$ propionate $\mathrm{Hcl}$.

Structurally esmolol is very similar to metaprolol. Para substitute onaromatic ring imparts cardioselectivity to esmolol as it does to metoropolol. The presence of ester group in the para position imparts metabolic lability to esmolol and is responsible for it's short duration of action. The ester is rapidly hydrolysed by erythrocyte esterases. ${ }^{[5]}$

Clinical Pharmacology studies in normal volunteers have confirmed the beta blocking activity of Esmolol showing reduction of Heart rate at rest and during exercise, and attenuation of isoproterenol induced tachycardia. Blood levels of Esmolol have been shown to correlate with extent of beta blockade. After termination of infusion, substantial recovery from beta blockade is observed in 10-20 min.

In Human electrophysiology studies Esmolol produced effects typical of a beta blocker: a decrease in the heart rate 
(R), increase I sinus cycle length, prolongation of the sinus node recovery time, prolongation of $\mathrm{A}-\mathrm{V}$ interval during sinus rhythm and actual pacing and an increase in antegradewenckebach length. Esmolol in dosage of $>200$ $\mathrm{mcg} / \mathrm{kg} / \mathrm{min}$. produced reduction in heart rate $(\mathrm{R})$, systlic Blood pressure $(\mathrm{P})$ rate pressure product (RPR) Right and left ventricular ejection fraction, and cardiac index at rest. ${ }^{[6]}$ Which is similar to propranolol $4 \mathrm{mg}$. same results are reproduced during exercise also.

The relative cardio selectivity of esmolol is studied in comparison with propranolol. In asthmatic patents requiring no broncho dilator therarpy in esmolol group in therapeutic dosage.

\section{Subjects and Methods}

Seventy five (75) patients belonging to ASA grade $1 \& 2$ scheduled for general surgical, orthopaedic surgical, ENT, gynocological surgical producers were studied. The age of the patients varied from 10 to 60 years.

\section{Procedure}

The patients were studied in groups A,B, and C.

Group "A" Patients served as control.

Group "B" in this group patients received intra-venous xylocard $1.5 \mathrm{mg} / \mathrm{kg}$

Group "C" - This group received intravenous esmolol hydrochloride $500 \mathrm{mcg} \mathrm{kg}-1$.

\section{Technique:-}

All the patients in the groups $\mathrm{A}, \mathrm{B}$ and $\mathrm{C}$ were induced with thiopentone sodium $5 \mathrm{mg} \mathrm{kg}-1$ and succinylcholine $1.5 \mathrm{mg}$ $\mathrm{kg}-1$. All the patients were pre-oxygenated for 3 minutes before induction.

In group A, laryngoscopy was performed after the fasciculation's subsided using Macintosh laryngoscope and intubation performed with a suitable endotracheal tube, anaesthesia was the maintained with $60 \%$ Nitrous oxide and $40 \%$ oxygen.

In group B, laryngoscopy was performed after one minute of administering intravenous xylocard $1.5 \mathrm{mg} / \mathrm{kg}$. Xylocard was administered immediately after succinylcholine injected. Anaesthesia was then maintained with $60 \%$ Nitrous oxide ad $40 \%$ oxygen.

In group $\mathrm{C}$, laryngoscopy and intubation was performed after three minutes of administering intravenous esmolol hydrochloride $500 \mathrm{mcg} \mathrm{kg}-1$. Esmolol hydrochloride was given just after injection of Thiopentoe sodium anaesthesia was maintained with $60 \%$ Nitrous oxide and $40 \$$ oxygen.

In all the three groups $0.5 \%$ Halothane was started just after intubation to prevet the patients from becoming lighter.

\section{Monitoring devices used in the study were.}

Pulse oximeter to observe changes in Heart rate

Sphygmo monometer with cuff (manually operated) to check
Blood Pressure changes

Continuous ECG monitor occurrence of Arrythmias in lead 2.

\section{Results}

\section{Table 1: AGE and SEX distribution}

\begin{tabular}{|c|c|c|c|c|c|c|}
\hline \multirow{2}{*}{$\begin{array}{l}\text { Age In } \\
\text { Year }\end{array}$} & \multicolumn{2}{|l|}{$\mathbf{A}$} & \multicolumn{2}{|l|}{ B } & \multicolumn{2}{|l|}{ C } \\
\hline & $\mathbf{M}$ & $\mathbf{F}$ & $\mathbf{M}$ & $\mathbf{F}$ & $\mathbf{M}$ & $\mathbf{F}$ \\
\hline $11-20$ & 2 & 2 & 3 & 2 & 1 & 1 \\
\hline $21-30$ & 5 & 4 & 4 & 3 & 5 & 3 \\
\hline $31-40$ & 2 & 4 & 4 & 1 & 2 & 2 \\
\hline $41-50$ & 2 & 2 & 2 & 2 & 5 & 2 \\
\hline $51-60$ & 1 & 1 & 2 & 2 & 3 & 1 \\
\hline Total & $12+$ & $13=25$ & $15+$ & $10=25$ & $16+$ & $9=25$ \\
\hline
\end{tabular}

Table 2: Nature of Surgery.

\begin{tabular}{|l|l|l|l|l|}
\hline Sl.No. & Nature Of Surgery & A & B & C \\
\hline 1 & $\begin{array}{l}\text { Exploratory laparotomy, } \\
\text { Cholecystemctomy, } \\
\text { Herniorrhaphy, } \\
\text { G-J with vagotomy, } \\
\text { Splenectomy. }\end{array}$ & 13 & 4 & 9 \\
\hline 2 & $\begin{array}{l}\text { Thoracic ad lumbar } \\
\text { Laminectomy }\end{array}$ & 2 & 3 & 2 \\
\hline 3 & $\begin{array}{l}\text { Thyroidectomy } \\
\text { Thoracotomy }\end{array}$ & 6 & 10 & 8 \\
\hline 4 & $\begin{array}{l}\text { Phylolithotomy } \\
\text { Nephrectomy } \\
\text { Vescical calculus }\end{array}$ & 0 & 1 & 2 \\
\hline 5 & $\begin{array}{l}\text { Abdominal and } \\
\text { Vaginal hysterectomies }\end{array}$ & 0 & 1 & 2 \\
\hline 6 & $\begin{array}{l}\text { Upper limb orthopaedic } \\
\text { Procedures. }\end{array}$ & 0 & 2 & 0 \\
\hline 7 & $\begin{array}{l}\text { Tonsilectomes Nasal } \\
\text { Polypectomy }\end{array}$ & 0 & 3 & 0 \\
\hline Miscellaneous & 4 & 1 & 2 \\
\hline
\end{tabular}

General surgical cases constituted $66.67 \%$ (50) of the cases selected for the study. In group "A" $88 \%$ (22) in group "B" $44 \%$ (11) and in groups "C" $68 \%(17)$ of the cases underwent general surgical procedures. About 18 (Eighteen) patients in group "A",B and "C". where hypertensive with blood pressure more than 140/90 $\mathrm{mm} \mathrm{Hg}$.

All patients belonged to ASA grade 1 and 2

Table 3: The changes in heart rate during various stages

\begin{tabular}{|l|l|l|l|}
\hline Timing & A & B & C \\
\hline Basal & $78+/-9$ & $85+/-15$ & $86+/-15$ \\
\hline Pre-induction & $86+/-10$ & $94+/-17$ & $96+/-15$ \\
\hline Just before laryngoscopy & $93+/-12$ & $99+/-13$ & $97+/-11$ \\
\hline LARYNGOSCOPY + ETI & $107+/-13$ & $109+/-12$ & $108+/-15$ \\
\hline 1ST MIN AFTER ETI & $106+/-10$ & $106+/-11$ & $106+/-15$ \\
\hline 2ND MIN AFTER ETI & $108+/-10$ & $100+/-12$ & $103+/-15$ \\
\hline 5TH MIN AFTER ETI & $102+/-11$ & $98+/-12$ & $99+/-14$ \\
\hline
\end{tabular}

ETI=Endotracheal intubation

Table 4: The difference in heart rate after induction and endotracheal intubation compared to pre induction levels.

\begin{tabular}{|l|l|l|l|}
\hline Sl. No & A & B & C \\
\hline Just Before Laryngoscopy & +17 & +5 & +1 \\
P & $>0.05$ & $>0.05$ & $>0.05$ \\
Remarks & N.S & N.S & N.S \\
\hline Laryngoscopy + ETI & +11 & +15 & +12 \\
P & $<0.001$ & $<0.001$ & $<0.001$ \\
Remarks & V.H.S & V.H.S & V.H.S \\
\hline \multicolumn{4}{|l}{ N.S=Not Significant }
\end{tabular}

V.H.S=Very Highly Significant. 
0

Heart rate at 5 th minute after endotracheal intubation is compared with that of at laryngoscopy and end endotracheal intubation.

Table 5: Heart rate at 5th minute after endotracheal intubation
is compared with that of at laryngoscopy and end endotracheal
intubation
\begin{tabular}{|l|l|l|l|}
\hline & B & B & C \\
\cline { 2 - 4 } Mean Of The Differece & $-5+/-12$ & $-11+/-7$ & $-9+/-7$ \\
P & $>0.05$ & $<0.001$ & $<0.001$ \\
REMARKS & NS & VHS & VHS \\
\hline
\end{tabular}

In our study, the heart rate in controls (Group A) before induction was $86+/-10$ rose to $93+/-12$ and $107+/-13$ after induction and after laryngoscopy + ETI respectively. The changes seen after endotracheal intubation alone was statistically very highly significant $(<0.001)$.

In Group B, the pre induction heart rate was $94+/-17$, which increased to $99+/-13$, after induction. This increase not significant $(\mathrm{P}>0.05)$. There was an increases of 15 at laryngoscopy + ETI which was very highly significant $(\mathrm{P}<0.001)$.

In Group $C$, the pre induction heart rate of $96+/-15$ increased to $97+/-11$ at induction and to $108+/-15$ following endotracheal intubation.

The later change was very highly significant $(\mathrm{P}<0.001)$.

In all the three groups, the average increase of 12.67 beats / min was observed from pre induction levels following endotracheal intubation.

The increase in heart rate seen at laryngoscopy + ETI decreased after 5 minutes by 5 beats / min in groups A which was not significant $(\mathrm{P}>0.05)$ In group $\mathrm{B}$ and $\mathrm{C}$ the decrease was $11+/-7$ and $9+/-7$ respectively(beats/min) after 5 minutes. These changes were very highly significant $(\mathrm{P}<0.001)$

\section{Discussion}

Hypoxia and hypercarbia have been implicated as causes for increase in pylse and blood pressure (king B.D., - 1951, Katz R.L., - 1970). In our study hypoxia and hypercarbia was avoided by controlled ventilation technique and by adequate pre oxygenation of high risk group. The pressure due to laryngoscopy ad intubation occurs 30-40 seconds after laryngoscopy (Steeling R.K.1977. The presser response due to $\mathrm{CO} 2$ retention is delayed and less abrupt. ${ }^{[7]}$

A significant rise in heart rate was observed during laryngoscopy, which was similar to the finding of stilting R.K. (1976 and 1977) and Den linger (1974). The heart rate increase was similar in all the groups A,B and C. it increase by an average of 4 beats/minute following induction. The present study was done to measure the cardiovascular response to laryngotracheal stimulation and to find a simple, safe and effective method for diminishing the cardiovascular reaction. ${ }^{[8]}$

In our study we used IV lignocaine and IV esmolol to attenceate the response. Lignocaine was used in dose of 1.5 $\mathrm{mg} / \mathrm{kg}$ body weight and Esmolol $500 \mathrm{mcg} / \mathrm{kg}$. Bromage (1961) reports that the concentration of lignocaine will rise to $10 \mathrm{mcg} / \mathrm{ml}$ when $6 \mathrm{mg} / \mathrm{kg}$ given to patient In man toxic effect occur in conscious subjects at a plasma level of $5 \mathrm{mcg} / \mathrm{ml}$ and in anaesthetised patients at $10 \mathrm{mcg} / \mathrm{ml}$ when circulatory depression become obvious. In our study, the dose of ligncaine used was therefore considered to be within safe limits. No untoward toxic response occurred in any case in the dosage used. No untoward toxic response occurred in any case in the dosage used. Regarding esmolol toxicity occurred at the dosage of $5000-6250 \mathrm{mg} / \mathrm{kg} / \mathrm{min}$. Over $1-2$ min infusion resulted in Brady cardio, Hypotension, loss of consciousness. In our study dosage is too less to cause any toxic untoward responses. Promethazine and ephedrine was used since they reduced the anaesthetic requirements (miller A Forbear 1970) and sedative hypnotic and analgesics. They are not known to attenuate or augment the hemodynamic response to laryngoscope (Devault 1960) Atropine was totally avoided in our study. ${ }^{[9]}$

Hypoxia and hypercarbia have been implicated as causes for increase in pulse and blood pressure (King B.D.-1951. Katz R.L.-1970). In our study hypoxia and hypercarbia was avoided by controlled ventilation technique and by adequate pre oxygenation of high risk group. The pressure due to larygoscopy and intubation occurs 30-40 seconds after larygoscopy (Stoelting R.K.1977). The presser response due to $\mathrm{CO} 2$ retention is delayed and less abrupt. ${ }^{[10]}$

\section{Conclusion}

There was an increase in the heart rate by an average of 4 beats/min following induction and intubation. However it was reduced by 5 minutes in group $\mathrm{B}$ and reached awake levels in group $\mathrm{C}$ while it was persistent in Group A.

\section{References}

1. V. K. Srivastava, V. Nagle, S. Agrawal, D. Kumar, A. Verma, and S. Kedia, "Comparative evaluation of dexmedetomidine and esmolol on hemodynamic responses during laparoscopic cholecystectomy," Journal of Clinical and Diagnostic Research, vol. 9, no. 3, pp. 01-05, 2015.

2. A. Liberati, D. G. Altman, J. Tetzlaff et al., "The PRISMA statement for reporting systematic reviews and meta-analyses of studies that evaluate health care interventions: explanation and elaboration," Journal of Clinical Epidemiology, vol. 62, no. 10, pp. e1-34, 2009.

3. J. P. Higgins and S. Green, "Cochrane handbook for systematic reviews of interventions," Naunyn-Schmiedebergs Archiv für experimentelle Pathologie und Pharmakologie, vol. 2011, no. 14, p. S38, 2010.

4. B. Yavascaoglu, F. N. Kaya, M. Baykara, M. Bozkurt, and S. Korkmaz, "A comparison of esmolol and dexmedetomidine for attenuation of intraocular pressure and haemodynamic responses to laryngoscopy and tracheal intubation," European Journal of Anaesthesiology, vol. 25, no. 6, pp. 517-519, 2008.

5. S. Reddy, D. Balaji, and S. Ahmed, "Dexmedetomidine versus esmolol to attenuate the hemodynamic response to laryngoscopy and tracheal intubation: a randomized double-blind clinical study," International Journal of Applied and Basic Medical Research, vol. 4, no. 2, pp. 95100, 2014.

6. M. G. Prashant Dass, V. P. Banderao, and S. H. Vardhamane, "Comparative assessment of efficacy of lignocaine $(1.5 \mathrm{mg} / \mathrm{kg})$, esmolol (300 $\mu \mathrm{g} / \mathrm{kg})$, and dexmedetomidine $(0.5 \mu \mathrm{g} / \mathrm{kg})$ in minimizing the pressor response to laryngoscopy and intubation," International Journal of Basic \& Clinical Pharmacology, vol. 4, no. 2, p. 1, 2015.

7. H. Gupta and S. Vyas, "A comparative study of efficacy of intravenous dexmedetomidine and intravenous esmolol for attenuation of stress response during laryngoscopy and endotracheal intubation," International Journal of Basic \& Clinical Pharmacology, vol. 5, pp. $1803-1808,2016$.

8. V. Selvaraj and K. R. Manoharan, "Prospective randomized study to compare between intravenous dexmedetomidine and esmolol for attenuation of hemodynamic response to endotracheal intubation," 
0

Anesthesia Essays \& Researches, vol. 10, no. 2, pp. 343-348, 2016.

9. S. Sharma, O. P. Suthar, M. L. Tak et al., "Comparison of esmolol and dexmedetomidine for suppression of hemodynamic response to laryngoscopy and endotracheal intubation in adult patients undergoing elective general surgery: a prospective, randomized controlled doubleblinded study," Anesthesia Essays \& Researches, vol. 12, no. 1, pp.
262-266, 2018

10. D. N. Singh and D. D. Chauhan, "An observational study to compare the effects of dexmedetomidine and esmolol in attenuating the haemodynamicresponsetolaryngoscopy andendotrachealintubation," International Journal of Advanced Research, vol. 5, no. 1, pp. 1108$1113,2017$.

Copyright: () the author(s), publisher. Academia Anesthesiologica International is an Official Publication of "Society for Health Care \& Research Development". It is an open-access article distributed under the terms of the Creative Commons Attribution Non-Commercial License, which permits unrestricted non-commercial use, distribution, and reproduction in any medium, provided the original work is properly cited.

How to cite this article: Baig MA. Effects of Intubation on Heart Rate: Xylocard and Esmolol. Acad. Anesthesiol. Int. 2019;4(2):13-16.

DOI: dx.doi.org/10.21276/aan.2019.4.2.4

Source of Support: Nil, Conflict of Interest: None declared. 